\title{
Maintenance of Functional Human Cancellous Bone and Human Hematopoiesis in NOD/SCID Mice
}

\author{
Frédérique Hubin,* Chantal Humblet,* Zakia Belaid,* Roland Greimers, $\dagger$ \\ Jacques Boniver, $\dagger$ Albert Thiry, $\dagger$ and Marie-Paule Defresne* \\ *Department of Cytology and Histology and †Department of Pathological Anatomy, \\ University of Liège, Liège, 4000, Belgium
}

\begin{abstract}
Attempts were made to establish models to study interactions between marrow stromal cells and hematopoietic cells in vivo. The approach was to create a NOD-SCID-hu murine model of long-term human hematopoiesis by implantation of a human adult bone fragment. Nine to 12 weeks posttransplantation, human $\mathrm{CD} 45^{+}$cells were detected in the blood and the spleen of some mice. The histology of the human transplant showed that human bone fragment was viable at 9 weeks. Moreover, vessels of human origin, as assessed by immunohistochemical detection of human $\beta_{2}$-microglobulin, were observed in the mouse tissue surrounding the transplanted human fragment.
\end{abstract}

Key words: Hematopoiesis; Human bone fragment; NOD/SCID mice; In vivo model

\section{INTRODUCTION}

The understanding of the role of bone marrow microenvironment in human hematopoiesis has been hampered due to lack of a good animal model. Several approaches have been used to develop an animal model of human hematopoiesis including the engraftment of human hematopoietic cells into severe combined immunodeficient (SCID) mice $(5-7,10,16)$. But by using adult and fetal hematopoietic cells only a limited degree of human hematopoiesis was observed (8). There may be at least two explanations for this. First, the residual nonspecific immune system of SCID mice (NK cells and macrophages) may be a barrier to the survival of hematopoietic cells (9) in the mouse and, second, the human hematopoietic microenvironment may be required for efficient human hematopoiesis.

The effect of human hematopoietic microenvironment on hematopoiesis has been investigated in SCID mice. Human fetal bone was implanted into SCID mice. Fetal bone marrow cells were detected in the implanted bone and a small number of circulating human $\mathrm{CD} 45^{+}$ cells were found in the mouse blood but no data were provided on the infiltration of hematopoietic cells in other mouse tissues (7). Morever, this approach has limitations. Fetal tissues do not reflect adult hematopoietic conditions $(13,14)$. Heike et al. (3) implanted adult bone in SCID mice and also administered human cytokines at the site of bone implantation and detected circulating human cells in SCID mice only for the duration of cytokine administration. Implantation of adult bone in the absence of cytokine administration has failed (3). However, the regular administration of cytokines may skew the differentiation of human bone marrow cell populations.

Several approaches have been tried to overcome the SCID mouse immune barrier to human hematopoietic cells. The first one was to implant adult human bone in SCID mice pretreated with radiation and anti-asialo GM1 rabbit sera (13), which showed clearly that the main barrier to the successful implantation of viable human tissues in SCID mice is host macrophages and NK cells. An alternative is to implant human bone fragments into nonobese diabetes (NOD/SCID) mice, which are totally immunodeficient (14). Fujiki et al. implanted (2) human rib fragments in NOD/SCID and described a dominant expansion of human $\mathrm{T}$ lymphocytes in peripheral blood and fatty degeneration of marrow in the implanted bone fragments by 8 weeks. This approach also has some limitations. The human bones were obtained from lung cancer patients wherein the bone marrow could present reactive changes in response to the pathology and/or the treatment. In our hypothesis, NOD/SCID mice would be better recipients for human bone marrow

Accepted July 9, 2004.

Address correspondence to Frédérique Hubin, Department of Cytology and Histology, University of Liège, BAT.B23, avenue de l'Hopital, 3, 4000 Liège 1, Belgium. Tel: 003243662403; Fax: 003243662919; E-mail: F.Hubin@ulg.ac.be 
than SCID mice. No pretreatment is necessary to deplete residual NK cells and macrophages of SCID mice and we postulate that adult bone marrow fragment containing an intact hematopoietic microenvironment would sustain human hematopoiesis for several weeks.

We thus implanted normal human bone fragments into NOD/SCID mice and we looked for human hematopoiesis in these animals. The adult human bone fragment implanted was viable and functional at 9 weeks posttransplant and human hematopoiesis was maintained for 12 weeks.

\section{MATERIALS AND METHODS}

\section{Antibodies}

Mouse IgG anti-human CD45 antibody (Becton Dickinson) conjugated with fluorescein isothiocyanate (FITC) was used to detect pan-leucocytes of human origin. Mouse $\operatorname{Ig} \mathrm{M}$ anti-human $\beta_{2}$-microglobulin antibody (Pharmingen) stains human cells that express HLA class I antigen complex. Rabbit IgM anti-mouse conjugated with biotin was used to reveal the $\beta_{2}$-microglobulin staining.

Rabbit IgG anti-human von Willebrand factor antibody (Dako) was used to identify the presence of blood vessels. Goat $\operatorname{IgG}$ anti-rabbit conjugated with biotin and peroxidase (Dakocytomation envision $+{ }^{\text {(1) }}$ system labeled polymer-HRP) was used to reveal the von Willebrand factor staining.

\section{Reagents}

Avidin-biotin-peroxidase was obtained from Vector, diaminobenzidine (DAB) was purchased from Merck, and bisbenzimide was from Sigma.

\section{Mice}

NOD/SCID mice were purchased from Jackson Laboratories (Bar Harbor, ME) and were maintained under specific pathogen-free conditions. Mice received nutritional chow and water ad libitum and were used when 6-8 weeks old. The experimental work was conducted according to the procedures outlined in the Law for Care and Use of Laboratory Animals (Arrêté Royal, November 14, 1993, Belgium).

\section{Origin of Human Bone}

Cancellous bone was obtained from healthy volunteer patients (age range 12-52 years) during hip surgery using protocols approved by the Human Ethics Committee. Cancellous bone was obtained from the posterior iliac crest, minced in small fragments approximately 0.5 $\mathrm{cm}$, and maintained under sterile conditions in RPMI1640 medium (Life Technologies).

\section{Implantation of NOD/SCID Mice With Human Bone}

Transplantation of bone into NOD/SCID mice was performed within $2 \mathrm{~h}$ of procurement, under a general anesthesia (Forene, S.A. Abbot). Human bone fragments were transplanted subcutaneously over the back of the animal.

\section{Tissue Processing for Histology and Preparation for Flow Cytometric Analysis}

At various time points (4, 6, 8, 9, 10, and 12 weeks), mice were killed by $\mathrm{CO}_{2}$ inhalation. Three mice were used for each endpoint. The human bone marrow was removed and fixed in Histocon ${ }^{\text {(P) }}$ (Polysciences Inc., Warrington, PA), embedded in Tissue-Tek ${ }^{\circledR}$ (O.C.T. compound), and frozen at $-80^{\circ} \mathrm{C}$.

The peripheral blood was taken from the retro-orbital sinus; bone marrow and spleen were collected. These tissues were teased apart and passed through a tissue filter (Blutex, $60 \mu \mathrm{m}$ ) to remove debris. After lysis of red blood cells with hypotonic saline solution $\left(\mathrm{NH}_{4} \mathrm{Cl}\right.$, $\mathrm{KHCO}_{3}$, and EDTA), white cells were incubated for 30 min at $4^{\circ} \mathrm{C}$ with a mouse anti-human CD45 antibody (mouse IgG conjugated with FITC), titrated with reference cells and used at saturating concentrations, and analyzed by flow cytometry. Cells were analyzed with a FACStar plus (Becton Dickinson) equipped with an argon neon laser. Specific fluorescence of FITC excited at $488 \mathrm{~nm}$ as well as forward and orthogonal light scatter signals were used to establish sort windows. Listmode analysis was done by using the CellQuest program (Becton Dickinson). Listmode data were obtained from more than 10,000 cells. Negative control consisted of additional aliquots of the same cells stained with irrelevant isotype-matched control antibody directly labeled with the identical fluorochrome. Positive control was human blood cells incubated with mouse anti-human CD45 antibody coupled to FITC. To separate human from mouse cells on the basis of their size, dot plot analysis was performed on human lymphocytes isolated from a buffy coat and on a cell suspension from murine spleen. To determine the threshold of detection of FACS analysis, human lymphocytes incubated for $30 \mathrm{~min}$ at $4^{\circ} \mathrm{C}$ with a mouse anti-human CD45 antibody conjugated with FITC were serially diluted in nonstained lymphocytes and the lowest percentage detected by flow cytometry was evaluated.

\section{Enzymology of Implanted Human Bone}

For alkaline phosphatase activity detection, 5- $\mu \mathrm{m}$ cryostat sections were incubated in a reaction medium containing $1 \mathrm{mg} \mathrm{m}^{-1}$ fast blue $\mathrm{BB}$ salt, $0.3 \mathrm{mg} \mathrm{ml}^{-1}$ naphthol-AS-phosphate (both Sigma, Poole, UK), and $0.5 \% N, N$-dimethylformamide in $0.2 \mathrm{M}$ Tris buffer $(\mathrm{pH}$ 9.1). To reveal the chloroacetate esterase expression, 
specimens were incubated in a reaction medium containing 2\% parafuchsin-hydrochloride (Fluka Chemie), 0.1 $\mathrm{mg} \mathrm{ml} \mathrm{m}^{-1}$ naphthol-ASD-chloroacetate (Sigma, Poole, $\mathrm{UK}$ ), and $1 \% \mathrm{~N}, \mathrm{~N}$-dimethylformamide in $0.15 \mathrm{M}$ Veronal buffer (pH 6.3).

\section{Histology and Immunohistology of Implanted Human Bone}

Endogenous peroxidase activity was inhibited by incubating the sections for $10 \mathrm{~min}$ in $3 \% \mathrm{H}_{2} \mathrm{O}_{2}$. Parallel sections were incubated for $2 \mathrm{~h}$ at room temperature with a mouse anti-human $\beta_{2}$-microglobulin antibody titrated with reference tissues and used at saturating concentrations, then with an anti-mouse $\operatorname{IgM}$ conjugated with biotin, and finally with avidin-biotin-peroxidase. After incubation in DAB, sections were counterstained with hematoxylin and eosin (Surgipath), mounted with entellan (Merck), and observed with a light microscope. Positive cells were stained in brown. For von Willebrand staining, endogenous peroxidase activity was also inhibited as described above. Sections were incubated for 30 $\mathrm{min}$ at room temperature with a rabbit anti-human von Willebrand antibody used at optimal dilutions, then with an anti-rabbit $\operatorname{IgG}$ coupled with biotin and peroxidase during $30 \mathrm{~min}$. After incubation for $3 \mathrm{~min}$ in DAB, sections were counterstained with hematoxylin and eosin, mounted with entellan, and observed with a light microscope. Endothelial positive cells were stained in brown.

For immunofluorescence, sections were incubated with a mouse anti-human CD45 antibody coupled with FITC. Positive cells were green cells. Nuclei were counterstained in blue with DAPI (bisbenzimide).

\section{RESULTS}

To develop an animal model for human hematopoiesis, we implanted fragments of healthy adult human bone into NOD/SCID mice. A small fragment of posterior iliac crest was subcutaneously implanted.

\section{Human Hematopoiesis in hu-Bone NOD/SCID Mice}

To detect the presence of human hematopoietic cells in hu-bone NOD/SCID mouse tissues, blood, spleen, and bone marrow of the animal retrieved at several time points postimplantation $(4,6,8,9,10$, and 12 weeks) were stained with a mouse anti-human CD45 antibody, which is a marker for pan-leucocytes. To identify human cells from mouse cells a scatter dot plot was used, which distinguishes human cells from mouse cells on the basis of their size (Fig. 1). The spikes indicate that murine cells and human cells have clearly different sizes on the basis of their SSC and FSC scatters.

To determine the threshold of detection of FACS analysis, we mixed human lymphocytes stained with a mouse anti-human CD45 antibody FITC with non-

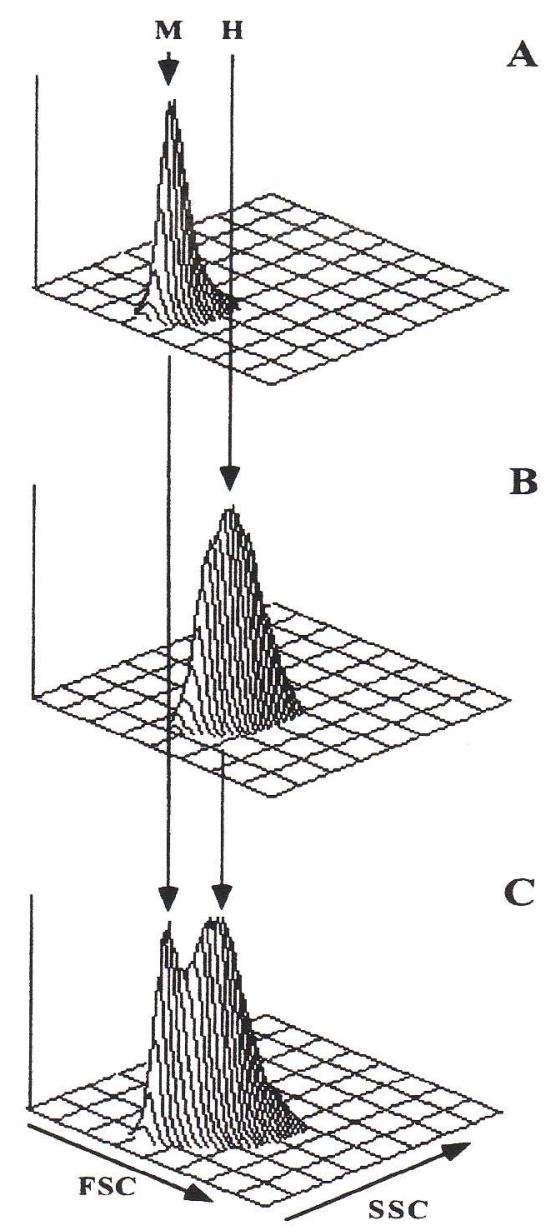

Figure 1. Identification of mouse $(\mathrm{M})$ and human $(\mathrm{H})$ cells in a scatter dot plot. (A) Spleen cells from a mouse, (B) human lymphocytes, (C) mouse and human cells are mixed in the same suspension. The spikes corresponding to their respective SCC and FSC scatters allows a clear distinction between both types of cells.

stained lymphocytes. FACS analysis allows to detect $0.01 \%$ of positive cells (Fig. 2).

To characterize expression of CD45 on human blood lymphocytes, three populations of cells are analyzed: lymphocytes (L), monocytes (M), and granulocytes $(\mathrm{G})$ (Fig. 3). Eighty percent of human blood cells were stained with anti-CD45 antibody with different fluorescent intensity: fluorescence of lymphocytes is at $10^{3}$, that of granulocytes at $10^{2}$, and that of monocytes is at an intermediate value.

Human cells, undetectable at 8 weeks posttransplant, began to emerge at 9 weeks in the blood, the spleen, and the bone marrow of some mice (Table 1). The results of one representative experiment are illustrated in Figure $4 \mathrm{~B}$ and $\mathrm{D}$. The human cells constituted $0.65 \%$ of circulating mononuclear cells and $0.23 \%$ of spleen mononuclear cells. At 12 weeks, the percentage of human cells 


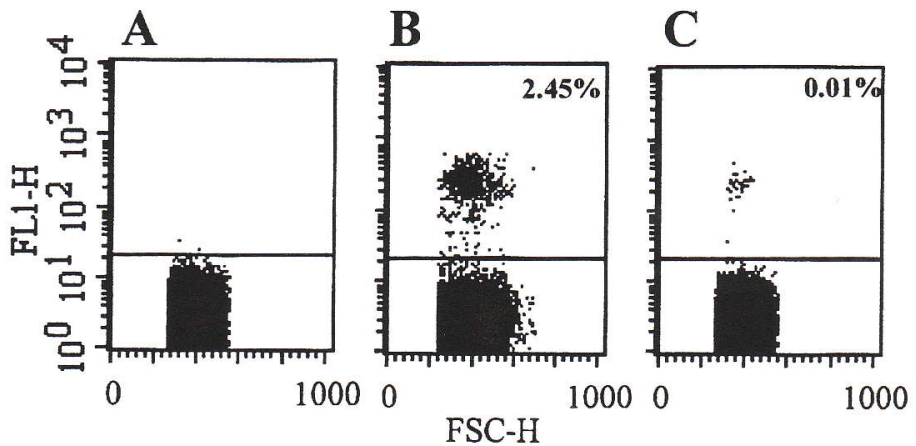

Figure 2. CD45 expression on human lymphocyte. (A) Negative cells and (B, C) positive cells (B) $2.45 \%$ positive cells are present in the cell suspension. (C) FACS analysis indicates as low as $0.01 \%$ positive cells diluted in negative cells.
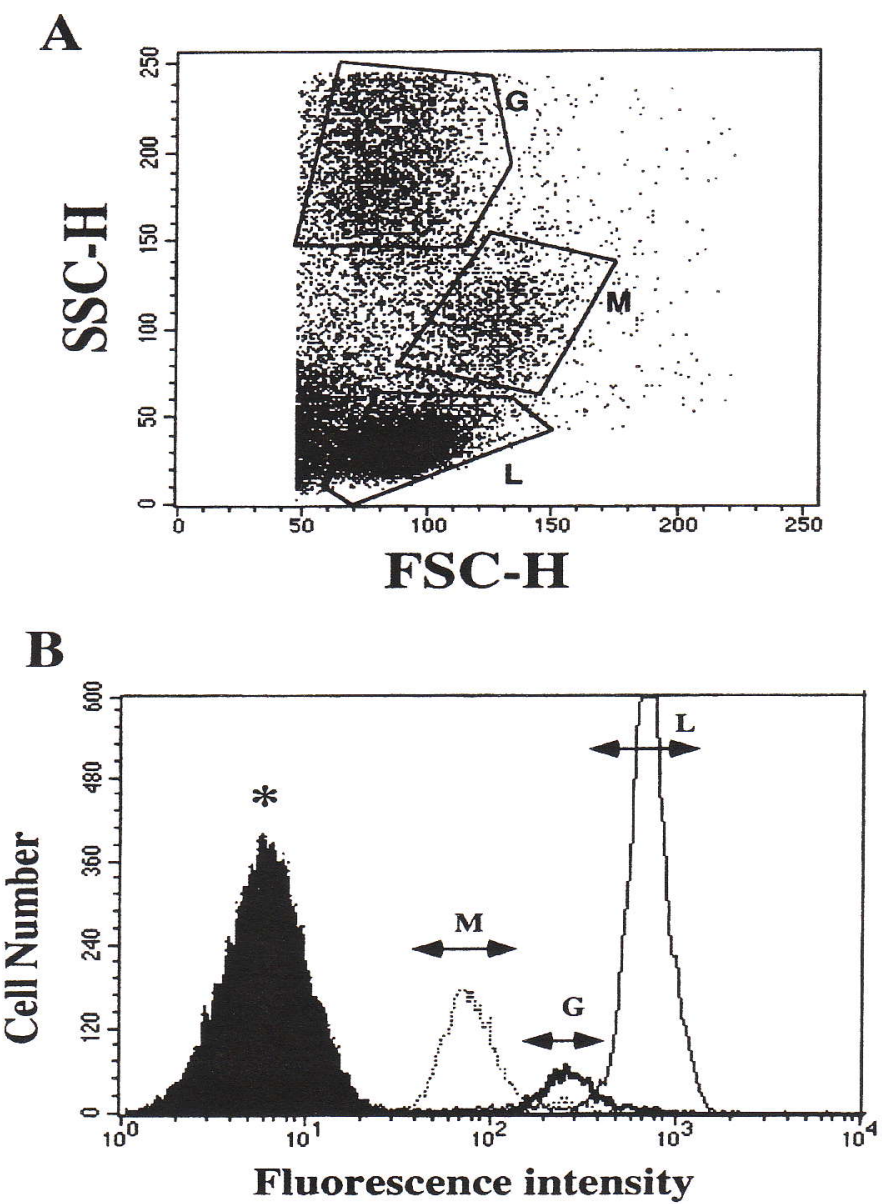

Figure 3. CD45 expression on human blood cells. Human blood cells were stained with CD45 antibody. The results indicate that $80 \%$ of these cells express this molecule: lymphocytes (L) at $10^{3}$, monocytes (M) at $10^{2}$, and granulocytes (G) at an intermediate value. *Negative control. 
Table 1. Presence of Human $\mathrm{CD} 45^{+}$Cells in NOD/SCID Mouse Tissues (Blood, Spleen, and Bone Marrow) at Several Time Points After Implantation

\begin{tabular}{ccccccc}
\hline & \multicolumn{7}{c}{ Weeks After Human Bone Graft } \\
\cline { 2 - 7 } & 4 & 6 & 8 & 9 & 10 & 12 \\
\hline Patient 1 & blood: $<0.1 \%$ & nd & blood: $<0.1 \%$ & blood: $0.65 \%$ & blood: $0.35 \%$ & nd \\
& spleen: $<0.1 \%$ & nd & spleen: $<0.1 \%$ & spleen: $0.23 \%$ & spleen: $0.20 \%$ & nd \\
& BM: $<0.1 \%$ & nd & BM: $<0.1 \%$ & BM: $<0.1 \%$ & BM: $<0.1 \%$ & nd \\
Patient 2 & nd & blood: $<0.1 \%$ & blood: $<0.1 \%$ & nd & nd & blood: $0.10 \%$ \\
& nd & spleen: $<0.1 \%$ & spleen: $<0.1 \%$ & nd & nd & spleen: $0.10 \%$ \\
& nd & BM: $<0.1 \%$ & BM: $<0.1 \%$ & nd & nd & BM: $<0.1 \%$ \\
\hline
\end{tabular}

found in mouse blood and spleen mononuclear cells was $0.1 \%$. The fluorescence intensity of these cells corresponds to that of lymphocytes.

\section{Histology and Immunohistology} of Implanted Human Bone

Immunohistological and histological analysis of adult human bone implants in NOD/SCID mice was performed at different times posttransplantation. By 9 weeks, human bone implant was viable, as shown in Figure 5A. Active osteoblasts, osteocytes, and osteoiddeposited surface were present near the new bone formed (Fig. 5A). Numerous blood vessels identified by an anti-von Willebrand factor antibody were observed in the mouse tissue surrounding the bone implant (Fig. $5 \mathrm{C})$. The human origin of these vessels was assessed using an anti-human $\beta_{2}$-microglobulin (specific for HLA class I antigen complex) antibody, which also allows to

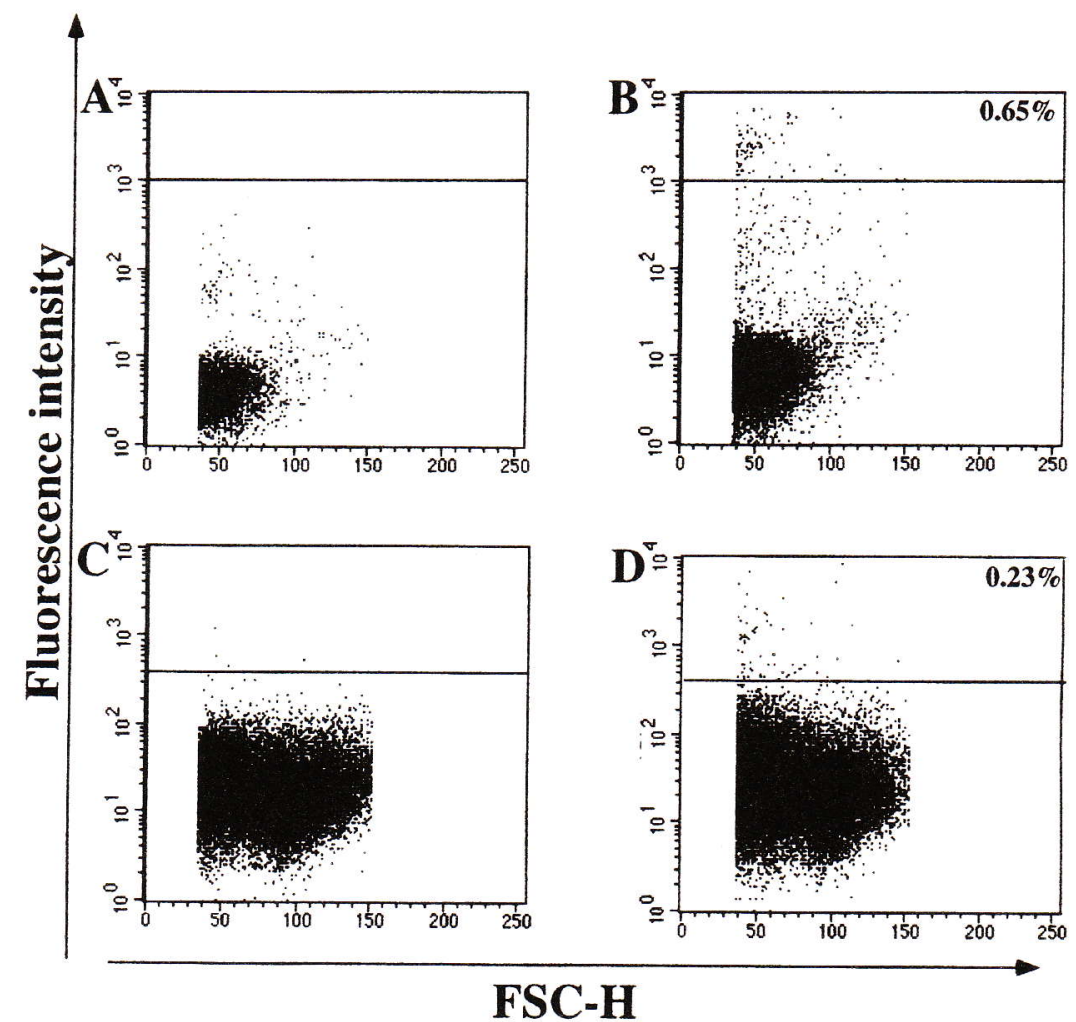

Figure 4. CD45 expression in the (A) blood and (B) spleen of a NOD/SCID mouse 9 weeks after human bone implantation. The blood contains $0.65 \%$ of human leukocyte $\mathrm{CD} 45^{+}$and the spleen contains $0.23 \%$ of human $\mathrm{CD}_{4} 5^{+}$cells. $(\mathrm{A}, \mathrm{C})$ Negative controls and (B, D) cells stained with antihuman CD45 antibody. 

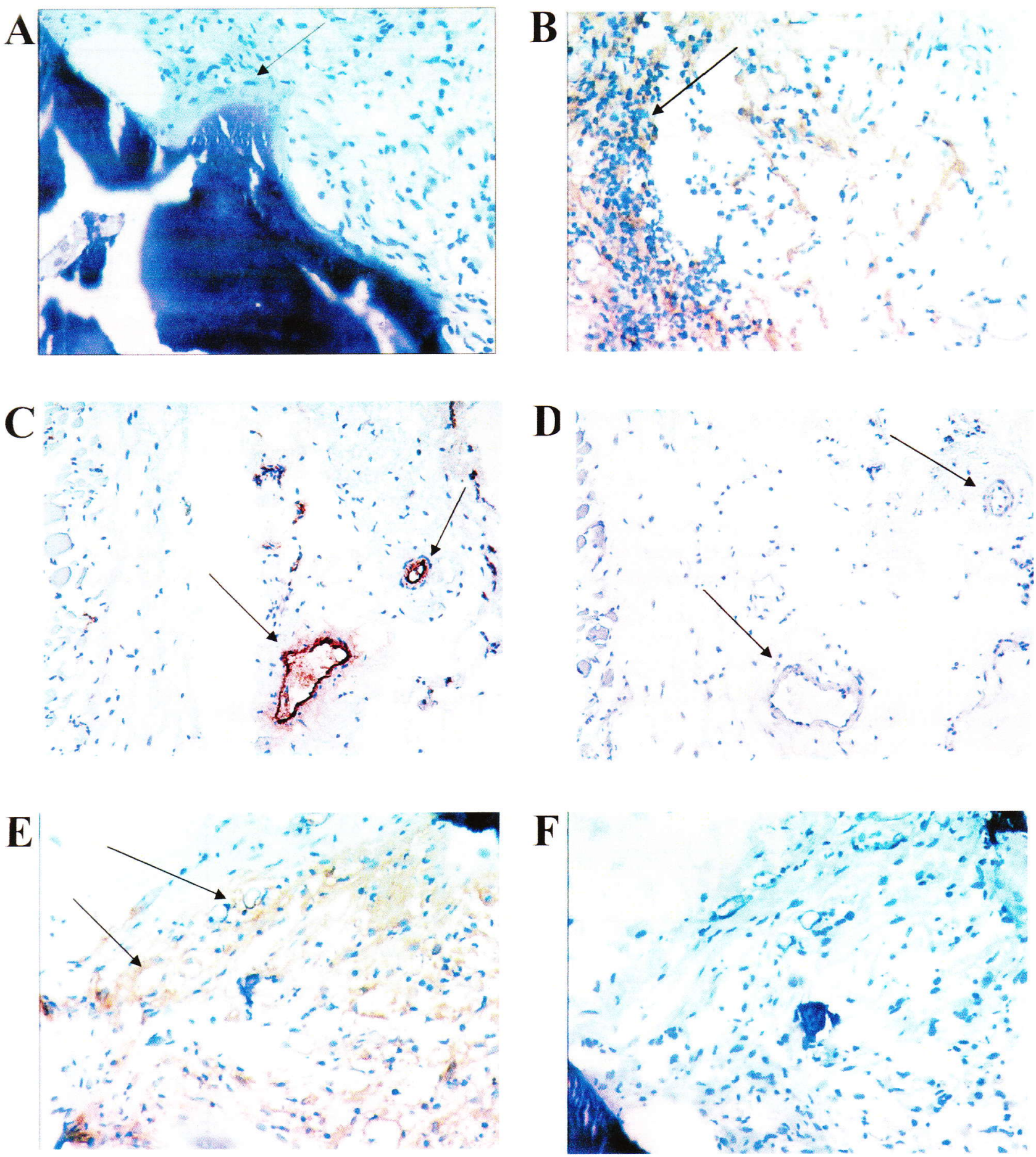

Figure 5. Histological and immunohistological analysis of human bone 9 weeks after transplantation in a NOD/SCID mouse. Sections were stained with (A) hematoxylin and eosin, (B, E) anti-human $\beta_{2}$-microglobulin, and (C) anti-von Willebrand factor. (D, F) Negative controls. Human viable bone and osteoid surface (arrow) are seen in (A). Hematopoietic foci are shown (arrow) in human tissue in (B). Blood vessels are identified in murine tissues surrounding the graft (arrows) in (C), which are of human origin $(\mathrm{E})$. 

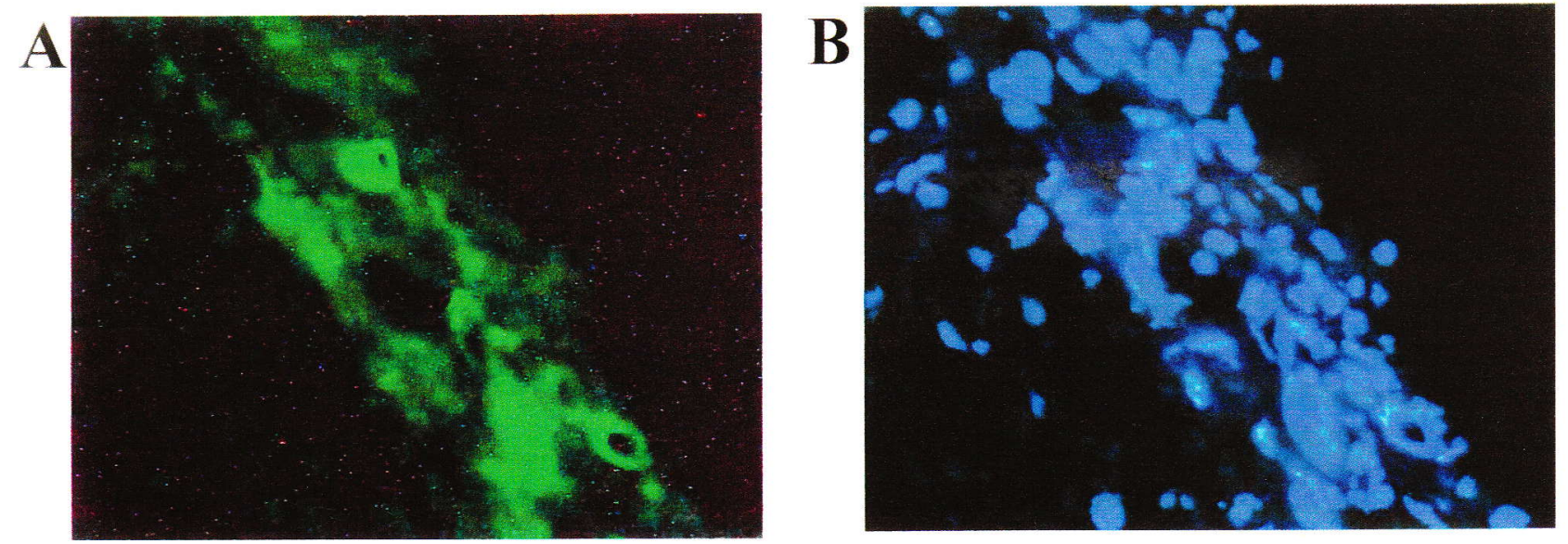

Figure 6. Immunofluorescence analysis of human bone 9 weeks after transplantation in a NOD/SCID mouse. CD $45^{+}$cells can be observed in green (A) and nuclei are colored in blue with DAPI (B).

demonstrate human hematopoietic foci (Fig. 5E and B). Immunostaining with anti-CD45 antibodies revealed that some cells of the hematopoietic foci observed in the human bone fragment express CD45 (Fig. 6A).

\section{Enzymology of Implanted Human Bone}

Enzymology analysis of adult human bone implants in NOD/SCID mice was performed on cryostat sections. By 9 weeks, cells of the myeloid lineage (colored in red) were found in the human bone marrow (Fig. 7A); they were surrounded by cytoplasmic processes of fibroblastic-like cells that expressed alkaline phosphatase (Fig. 7B).

\section{DISCUSSION}

Several reports on human hematopoiesis in SCID mice, after implantation of either human fetal bone or injection of fetal bone marrow cells, have been published $(6,7)$. However, embryonic and adult hematopoietic progenitors differ with respect to cycling rates, responses profiles to hematopoietic factors, and differentiation capacities (7). Others have reported about transplantation of adult human bone into SCID mice. Heike et al. (3) reported that human hematopoietic cells were viable in SCID mice only when human cytokines were administered at the site of bone implantation. Fujiki et al. (2) transplanted adult human bone in NOD/SCID mice and described dominant expansion of human $\mathrm{T}$ cells with fatty degeneration of marrow in the implanted bone fragment by 8 weeks.

In this report, we document the successful implantation of viable human bone into NOD/SCID mice. Osteoblastic cells survived and were functional up to at least 9 weeks as demonstrated by osteoid deposit on the bone
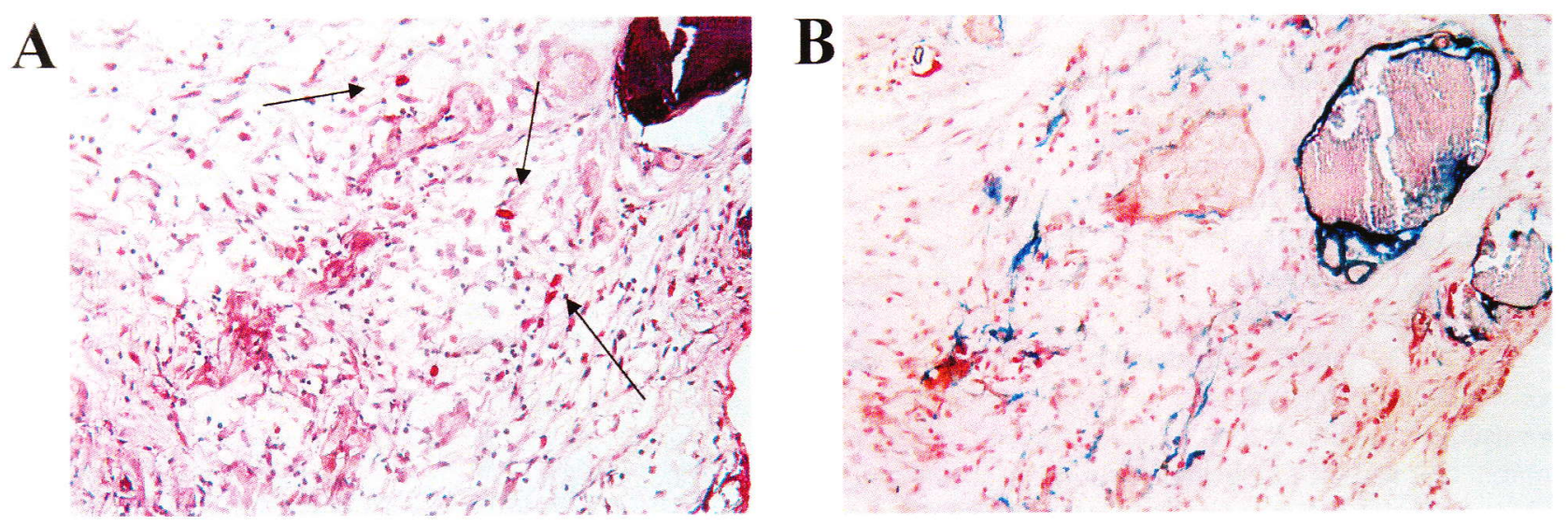

Figure 7. Enzymological analysis of human bone 9 weeks after transplantation in a NOD/SCID mouse. Chloroacetate esterases (in red) are present in hematopoietic foci of the myeloid lineage (A, arrows). The are surrounded by cytoplasmic processes expressing alkaline phosphatase (in blue, B). 
surface. The reason for this discrepancy in bone viability may result from the origin of transplanted bone. We implanted bone from the posterior iliac crest from healthy patients rather than rib fragments from patients suffering from cancer, wherein bone marrow could be altered by the pathology and/or treatment. Immunohistological analysis of human bone graft demonstrated the presence of human vessels in mouse tissues surrounding the transplanted human fragment. They probably ensure the migration of human blood cells from human bone marrow to the mouse tissues: human $\mathrm{CD} 45^{+}$cells were observed in the transplanted bone fragment by 9 weeks. At 9 weeks, NOD/SCID-hu tissue cells were analyzed by flow cytometry for human CD $45^{+}$cells and showed that $0.65 \%$ and $0.23 \%$ of human cells are recovered in blood and spleen, respectively, of the host animal. Human cells were still present at 12 weeks. Clearly, human hematopoietic cells from the implanted bone fragment were able to home and to persist in the murine tissues. During the first 8 weeks, we did not find any human cells, but that is not surprising. Previous studies (12) describe that at 3 weeks posttransplantation human bone marrow underwent a crisis phase due to poor vascularization of the human graft and characterized histologically by a rarefaction of bone marrow medullar cells. This aplasia was transient, because the same authors demonstrated a recovery of bone marrow by 12 weeks.

The number of human cells observed in the peripheral blood of the recipient was low. This can be explained by the reduced size of human fragment: we can estimate the number of human stem cells engrafted at about 24,000 per graft (1). The percentage of human cells in the blood of the recipient is indeed directly proportional to the quantity of human cells injected, so in many experiences $(4,11,15)$ several million were injected. The full phenotype of human blood cells recovered into NOD/SCID mice has not been analyzed. However, the fluorescence of $\mathrm{CD} 45^{+}$cells corresponds to that of lymphocytes. Moreover, some hematopoietic foci observed in the implanted bone belong to the myeloid lineage as assessed by the presence of chloroacetate esterases; they were surrounded by alkaline phosphatasepositive fibroblastic-like cells resembling those described by Western-Bayton (17). These observations suggest that the implanted bone fragment sustains lymphopoiesis and granulopoiesis.

This model differs from those previously described: we implanted only human bone rather than fetal bone; we used no cytokines such as IL-3 or SCF; we did not inhibit $\mathrm{NK}$ and macrophage functions with anti-asialo GM1 sera; we did not irradiate recipient mice before transplantation. There are also differences in the mouse strain used: NOD/SCID versus SCID. The results show that this model is suitable to analyze adult stromal- hematopoietic cell interactions in vivo. With further efforts to refine the experimental protocol, it will be possible to extend use of this model to biopsies coming from patients suffering from hematological malignancies.

ACKNOWLEDGMENTS: This work was supported by the Belgian Fund for Medical Scientific Research (Télévie grant) with a grant from the Leon Fredericq Fund.

\section{REFERENCES}

1. Civin, C. L.; Banquerigo, M. L.; Strauss, L. C.; Loken, M. R. Antigenic analysis of hematopoiesis VI. Flow cytometric characterization of My-10-positive progenitor cells in normal human bone marrow. Exp. Hematol. 15:10-17; 1987.

2. Fujiki, Y.; Onodera, M.; Yamaguchi, T.; Osawa, M.; Sudo, K.; Hamada, H.; Ema, H.; Shibuya, A.; Takiguchi, M.; Kudo, T.; Nakauchi, H. Dominant expression of human $\mathrm{T}$ cells in non-obese diabetic/severe combined immunodeficiency mice implanted with human bone fragments. Exp. Hematol. 28:792-801; 2000.

3. Heike, Y.; Ohira, T.; Takahashi, M.; Saijo, N. Long-term human hematopoiesis in SCID-hu mice bearing transplanted fragments of adult bone and bone marrow cells. Blood 86:524-530; 1995.

4. Humeau, L.; Chabannon, C.; Firpo, M. T.; Mannoni, P.; Bagnis, C.; Roncarolo, M. G.; Namikawa, R. Successful reconstitution of human hematopoiesis in the SCID-hu mouse by genetically modified, highly enriched progenitors isolated from fetal liver. Blood 90:3496-3506; 1997.

5. Kamel-Reid, S.; Dick, J. E. Engraftment of immunedeficient mice with human hematopoietic stem cells. Science 242:1706-1709; 1988.

6. Kollmann, T. R.; Kim, A.; Zhuang, X.; Hachamovitch, M.; Goldstein, H. Reconstitution of SCID mice with human lymphoid and myeloid cells after transplantation with human fetal bone marrow without the requirement for exogenous human cytokines. Proc. Natl. Acad. Sci. USA 91: 8032-8036; 1994

7. Kyoizumi, S.; Baum, C. M.; Kaneshima, H.; McCune, J. M.; Yee, E. J.; Namikawa, R. Implantation and maintenance of functional human bone marrow in SCID-hu mice. Blood 79:1704-1711; 1992.

8. Lapidot, T.; Pflumio, F.; Doedens, M.; Murdoch, B.; Williams, D. E.; Dick, J. E. Cytokine stimulation of multilineage hematopoiesis from immature human cells engrafted in SCID mice. Science 255:1137-1141; 1992.

9. Murphy, W. J.; Kumar, V.; Bennett, M. Acute rejection of murine marrow allografts by natural killer cells and $T$ cells. Differences in kinetics and target antigen recognition. J. Exp. Med. 166:1499-1509; 1987.

10. Nolta, J. A.; Hanley, M. B.; Kohn, D. B. Sustained human hematopoiesis in immunodeficient mice by cotransplantation of marrow stroma expressing human IL-3: Analysis of gene transduction of long-lived progenitors. Blood 83: 3041-3051; 1994

11. Noort, W. A.; Willemze, R.; Falkenburg, J. H. Comparison of repopulating ability of hematopoietic progenitors cells isolated from human umbilical cord blood or bone marrow cells in NOD/SCID mice. Bone Marrow Transpl. 22:S58-S60; 1998.

12. Sandhu, J.; Shpitz, B.; Gallinger, S.; Hozumi, N. Human primary immune response in SCID engrafted with huPBLs. J. Immunol. 152:3806-3813; 1994. 
13. Sandhu, J. S.; Clark, B. R.; Boynton, E. L.; Atkins, H.; Messner, H.; Keating, A.; Hozumi, N. Human hematopoiesis in SCID mice implanted with human adult cancellous bone. Blood 88:1973-1982; 1996.

14. Shultz, L. D.; Schweitzer, P. A.; Christianson, S. W.; Gott, B.; Schweitzer, I. B.; Tennent, B.; McKenna, S.; Mobraaten, L.; Rajan, T. V.; Greiner, L. D.; Leiter, E. Multiple defects in innate and adaptive immunologic function in NOD/LtSz-scid mice. J. Immunol. 154:180-191; 1995.

15. van der Loo, J. C.; Hanenberg, H.; Cooper, R. J.; Luo, F. Y.; Lazaridis, E. N.; Williams, D. A. Nonobese dia- betic/severe combined immunodeficiency (NOD/SCID) mouse as a model system to study the engraftment and mobilization of human peripheral blood stem cells. Blood 92:2556-2570; 1998

16. Vormoor, J.; Lapidot, T.; Pflumio, F.; Risdon, G.; Patterson, B.; Broxmeyer, H. E.; Dick, J. E. Immature human cord blood progenitors engraft and proliferate to high levels in severe combined immunodeficient mice. Blood 83: 2489-2497; 1994.

17. Westen, H.; Bainton, D. F. Association of alkaline-phosphatase-positive reticulum cells in bone marrow with granulocytic precursors. J. Exp. Med. 150:919-937; 1979. 